\title{
Caracterização do processo de poluição dos sedimentos do rio Apodi-Mossoró no trecho urbano de Mossoró-RN
}

\author{
Characterization of the pollution process of sediments of the \\ Apodi-Mossoró River in the urban stretch of Mossoró-RN
}

\author{
Joel Medeiros Bezerra ${ }^{1}$ \\ Rafael Oliveira Batista ${ }^{2}$ \\ Paulo Cesar Moura da Silva²
}

\begin{abstract}
Resumo
Em decorrência da constante presença de poluentes lançados nos corpos hídricos e da dificuldade de compreensão de informações referentes à condição dos sedimentos de rio, a caracterização de sua qualidade se torna imprescindível. Deste modo, teve-se como objetivo caracterizar e identificar os fatores determinantes sobre o processo de poluição dos sedimentos do leito do rio Apodi-Mossoró no trecho urbano de Mossoró-RN. Foram coletadas 30 amostras ao longo do curso do rio Apodi-Mossoró, dentro do trecho urbano-rural do município de Mossoró. Sendo realizadas análises da concentração total dos seguintes metais pesados: alumínio (Al), cádmio $(\mathrm{Cd})$, cobre $(\mathrm{Cu})$, cromo $(\mathrm{Cr})$, chumbo $(\mathrm{Pb})$, ferro $(\mathrm{Fe})$, manganês $(\mathrm{Mn})$, níquel ( $\mathrm{Ni}$ ) e zinco $(\mathrm{Zn})$. Aplicou-se os métodos estatísticos multivariados de Análise de Agrupamento Hierárquico (AAH) e Análise de Componentes Principais/Análise Fatorial (ACP/AF). A distribuição das concentrações dos parâmetros geoquímicos nos sedimentos do rio Apodi-Mossoró, foram fortemente influenciados pelas características dos locais de coleta e pela antropocidade. Agrupou-se os pontos amostrados em 4 grupos representativos quanto as características de amostragem, identificando possíveis locais com alterações propiciadas pela ação antrópica.
\end{abstract}

Palavras-chave: Análise multivariada. Pressão antrópica. Impactos da Urbanização. Metais pesados.

\begin{abstract}
Due to the constant presence of pollutants in the water bodies and the difficulty of understanding information regarding the condition of the river sediments, the characterization of its quality becomes essential. In this way, the objective was to characterize and identify the determinants of the pollution process of the sediments of the Apodi-Mossoró river bed in the urban stretch of Mossoró-RN. Thirty samples were collected along the course of the Apodi-Mossoró River, within the urban-rural stretch of the
\end{abstract}

\footnotetext{
1 Universidade de Federal Rural do Semi-Árido - UFERSA, Departamento de Tecnologia e Engenharias - DETEC, Pau dos Ferros, Rio Grande do Norte, Brasil. E-mail: joel.medeiros@ufersa.edu.br

2 Universidade de Federal Rural do Semi-Árido - UFERSA, Departamento de Ciências Ambientais e Naturais, Mossoró, Rio Grande do Norte, Brasil. E-mail: rafaelbatista@ufersa.edu.br; paulo.moura@ufersa.edu.br

Artigo recebido em: 24/01/2017. Aceito para publicação em: 11/12/2018.
} 
municipality of Mossoró. The results of the analysis of the total concentration of the following heavy metals: aluminum (Al), cadmium $(\mathrm{Cd})$, copper $(\mathrm{Cu})$, chromium $(\mathrm{Cr})$, lead $(\mathrm{Pb})$, iron $(\mathrm{Fe})$, manganese $(\mathrm{Mn})$, nickel And zinc (Zn). We applied the multivariate statistical methods of Hierarchical Group Analysis (AAH) and Principal Component Analysis/Factor Analysis (ACP/AF). The distribution of the concentrations of the geochemical parameters in the sediments of the Apodi-Mossoró River were strongly influenced by the characteristics of the collection sites and antropocity. The sampled points were grouped into 4 representative groups regarding the sampling characteristics, identifying possible sites with alterations caused by the anthropic action.

Keywords: Multivariate analysis. Anthropogenic pressure. Urbanization Impacts. Heavy metals.

\section{Introdução}

A bacia hidrográfica Apodi/Mossoró se encontra no Oeste Potiguar, sendo o mais importante corpo hídrico da região e responsável por grande parte do seu desenvolvimento sócio-econômico. No entanto, este desenvolvimento trouxe graves problemas que atingem a população: poluição e degradação do rio (Bezerra et al., 2013).

De acordo com Oliveira et al. (2009) e Rocha et al. (2009), apesar de sua importância sócio-econômica, a bacia hidrográfica do Apodi-Mossoró vem sofrendo constantes impactos derivados das atividades antrópicas, sendo estas ações provenientes da lixiviação de fertilizantes e defensivos agrícolas das diversas atividades agrícolas desenvolvidas na área de contribuição do segmento fluvial em apreço; carreamento de material alóctone; além das constantes descargas de esgotos domésticos e industriais lançados em toda a extensão da rede de drenagem da área de contribuição da bacia vertente.

Dentre os poluentes, os metais se destacam devido aos efeitos nocivos à saúde. Sua introdução nos corpos d'água ocorre naturalmente através do intemperismo e de processos geoquímicos. Além disso, as atividades antrópicas, industriais, domésticas e grandes cargas lançadas de maneira difusa, têm contribuído muito para a sua contaminação (CETESB, 2008). Vários trabalhos vêm sendo desenvolvidos com o interesse de quantificar a 
poluição por metais pesados em bacias hidrográficas, reunindo dados sobre o impacto ambiental e suas relações com as atividades econômicas, fornecendo subsídios para um melhor gerenciamento dos recursos naturais, tais como solo, água e a biomassa vegetal (Gardiman Junior, 2015; Alves, 2013; Guedes et al., 2012; Silva et al., 2011).

Como consequências do crescimento urbano e o aumento do consumo per capita de água, notam-se impactos ambientais negativos em função da degradação dos recursos naturais (Araújo et al., 2007; Umetsu et al., 2012).

Em geral, as bacias hidrográficas são ocupadas de maneira inadequada, resultando em deterioração dos recursos naturais (Bezerra et al., 2013). As ações antrópicas ocorrem principalmente devido ao uso inadequado do solo, estando estas associadas à deterioração nas áreas de recarga, os escoamentos superficiais excessivos, aporte exagerado de sedimentos e dejetos, resultando em assoreamento e poluição ambiental (Silva et al., 2009; Colet et al., 2013).

Segundo Jesus et al. (2004), para realizar uma avaliação do nível de contaminação em ecossistemas aquáticos, o estudo dos sedimentos tem enorme importância, pois este pode influenciar o metabolismo de todo o sistema devido a sua capacidade de acumular vários compostos como materiais orgânicas e inorgânicos (metais pesados) pelo processo de decantação e adsorção em áreas de baixa hidrodinâmica. Os sedimentos causam alterações nas condições dos sistemas ambientais e físico-químicas da água (Lima et al., 2001).

Os métodos de análise de dados multivariados são amplamente utilizados quando se deseja promover a redução do número de variáveis com o mínimo de perda de informação. O método dos componentes principais é um dos mais usados para resolver problemas clássicos de análise fatorial. Esta análise permite a redução do número de variáveis facilitando a extração de informações que serão de grande relevância na avaliação da qualidade das águas e no manejo da bacia (Andrade et al., 2007). 
Em decorrência do apresentado e da dificuldade de compreensão e harmonização de informações referentes à condição dos sedimentos de rio, a caracterização de sua qualidade se torna imprescindível, principalmente com o auxílio da estatística multivariada.

Deste modo, com o objetivo de caracterizar e identificar os fatores determinantes sobre o processo de poluição dos sedimentos do leito do rio Apodi-Mossoró no trecho urbano de Mossoró-RN, aplicou-se a análise estatística multivariada..

\section{Material e métodos}

O trabalho foi desenvolvido em um trecho do rio Apodi/Mossoró, localizado no município de Mossoró (Rio Grande do Norte, Brasil), com altitude média de 16 m e cujas coordenadas são: (UTM SAD69) 9426911.26 m Sul e 685285.56 m Oeste, fuso 24 Sul.

O Rio Apodi-Mossoró cruza a cidade de Mossoró no sentido sudoestenordeste (Figura 1), apresentando sinuosidade e com vários açudes e lagos nas proximidades de suas margens, exibindo três barramentos hidráulicos junto a área urbana (Araújo et al., 2007).

De acordo com a classificação climática de Koppen, o clima da região é do tipo BSwh', ou seja, quente e seco, característico de semiárido. A temperatura média anual é de $27,4^{\circ} \mathrm{C}$ e a precipitação pluviométrica anual irregular, com média de 673,9 mm e umidade relativa do ar de 68,9\%. 
Figura 1. Mapa do Brasil, localização da região Nordeste, estado do Rio Grande do Norte, Bacia Hidrográfica do Apodi-Mossoró e município de Mossoró

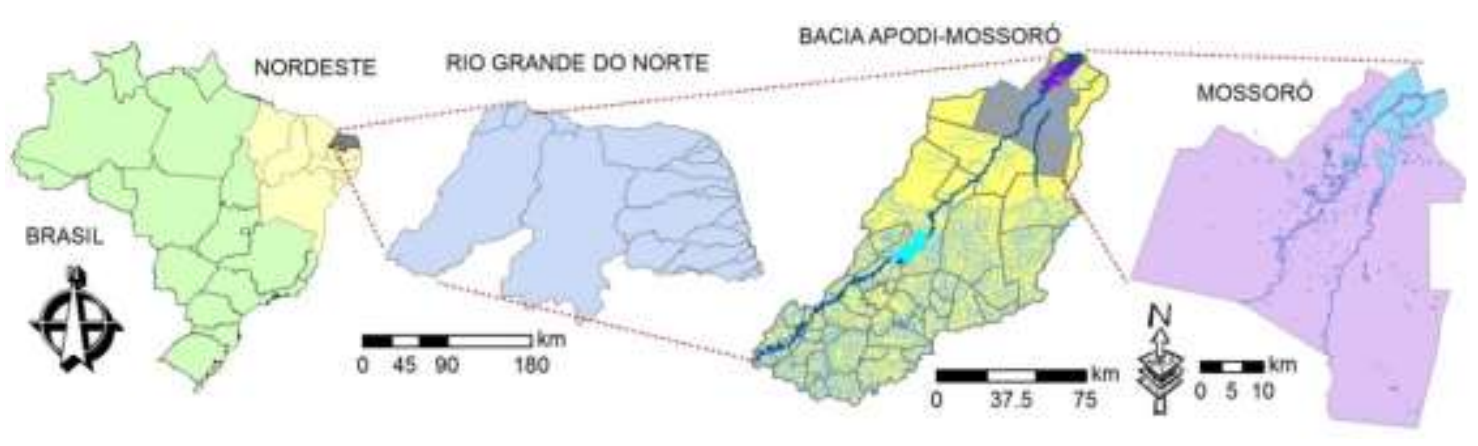

Org.: do Autor, 2018.

Os solos da região de estudo são classificados como Latossolo Vermelho Amarelo, Argissolo Vermelho-Amarelo, Nessolos Quartzarênicos, Cambissolos Háplicos e Neossolos Litólicos, de acordo com o sistema brasileiro de classificação de solos (EMBRAPA, 2006). De acordo com Mendes et al. (2010) os Cambissolos são predominantes na região, cujas principais características químicas com relação ao conteúdo de metais pesados são apresentadas na Tabela 1 .

Tabela 1. Características químicas dos teores médios de metais pesados do Cambissolo

\begin{tabular}{|c|c|c|c|c|c|c|c|}
\hline \multicolumn{8}{|c|}{ Conteúdo médio de metais pesados } \\
\hline $\mathrm{Cr}$ & $\mathrm{Cd}$ & $\mathrm{Ni}$ & $\begin{array}{c}\mathrm{Pb} \\
\mathrm{mg} \mathrm{kg}\end{array}$ & $\mathrm{Zn}$ & $\mathrm{Cu}$ & $\mathrm{Mn}$ & $\begin{array}{c}\mathrm{Fe} \\
\mathrm{g} \mathrm{kg}^{-1}\end{array}$ \\
\hline 89,00 & 0,83 & 109,83 & 18,67 & 93,00 & 95,17 & 280,83 & 13,38 \\
\hline
\end{tabular}

Foram coletadas 30 amostras ao longo do curso do rio, considerando o trecho original, antes do processo de tricotomização dos eixos, onde as amostras foram distribuídas na extensão do rio Apodi-Mossoró dentro do trecho urbano-rural do município de Mossoró. A escolha dos pontos levou em consideração a presença de atividades antrópicas adjacentes às margens do rio, conforme apresentado na Figura 2. 
Figura 2. Mapa de localização dos pontos de coletas de amostragem

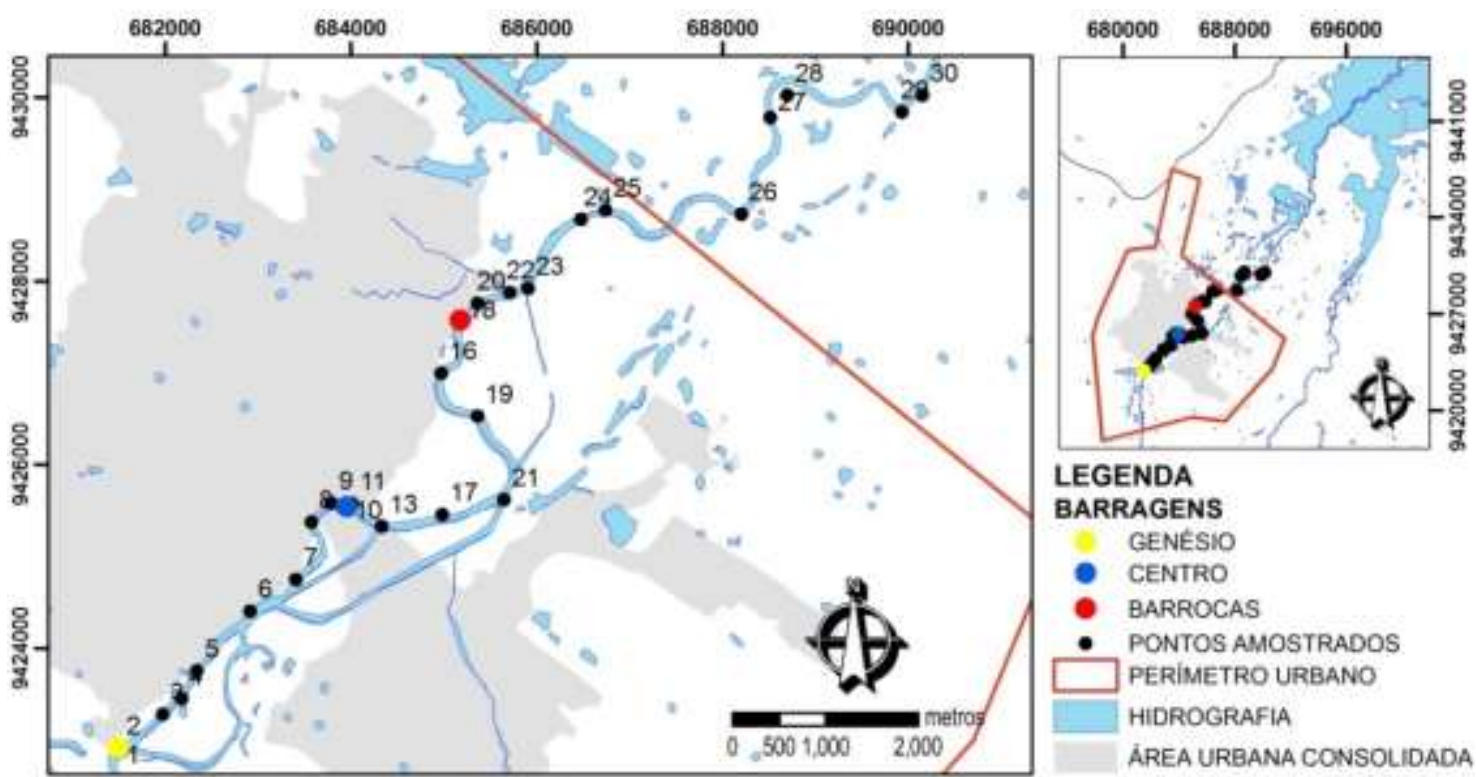

As amostras foram coletadas nos dias 05/05/2010, 22/05/2010 e 29/05/2010, considerando a ausência de eventos de precipitação (Figura 3), em virtude da extensão do corpo hídrico. No momento das amostragens a vazão média do rio era de $0,5 \mathrm{~m}^{3} \mathrm{~s}-1$. No entanto realizou-se a medição da lâmina de água do rio para cada local de amostragem, conforme Figura 4.

Figura 3. Distribuição diária do regime de precipitação pluvial (mm), no período de janeiro a junho de 2010

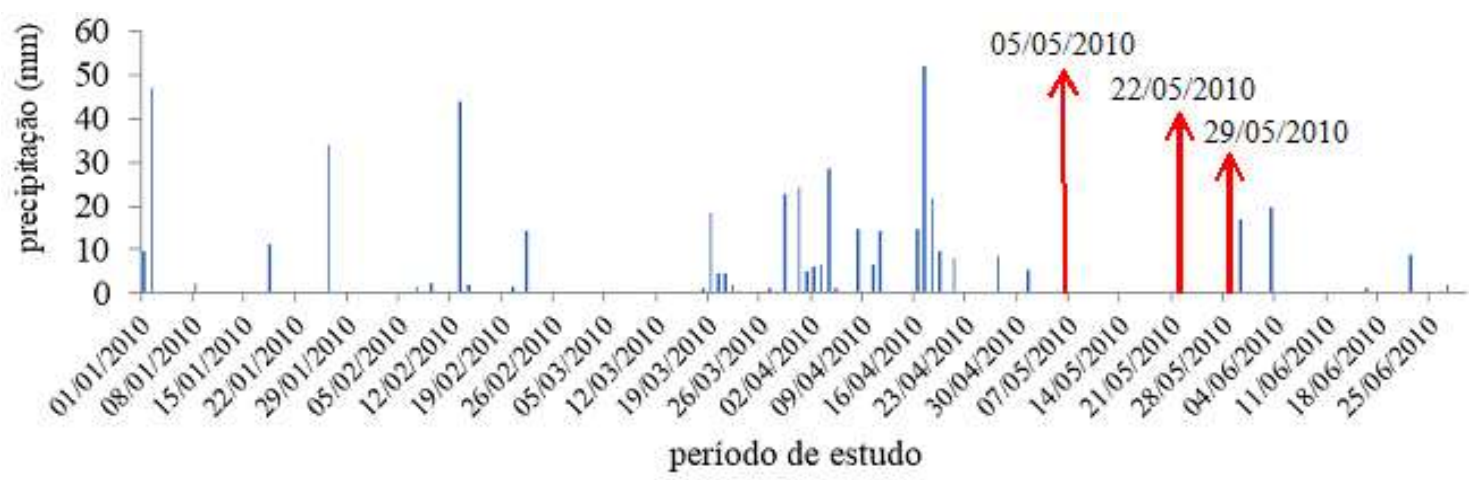


Figura 4. Distribuição das lâminas de água sobre a camada superficial das amostras

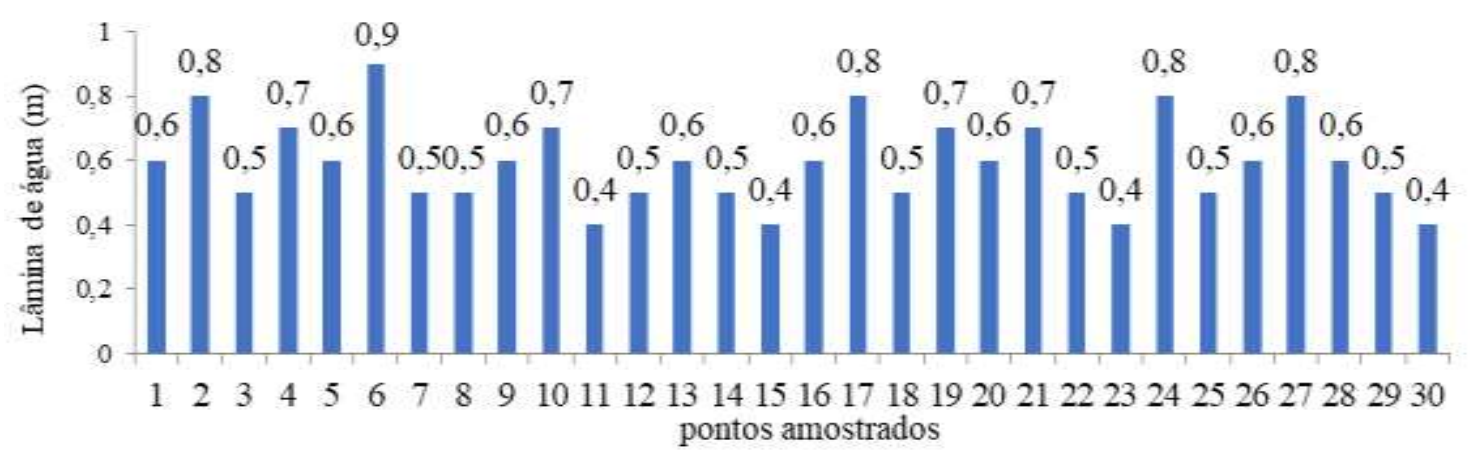

A coleta do sedimento superficial do leito do rio foi realizada na camada de 0,15 $\mathrm{m}$ de profundidade média, sempre próximas às margens do corpo hídrico, sendo utilizado um amostrador de dragagem. Em que um tubo amostrador foi introduzido no sedimento no sentido horizontal, armazenando uma coluna de sedimento coesivo e não-coesivo. As amostras foram coletadas com três repetições de amostras simples, compreendendo uma amostra composta, sendo cada ponto de amostragem georreferenciado com auxílio de receptor GPS.

Foram realizadas as análises da concentração total dos seguintes metais pesados: alumínio $(\mathrm{Al})$, cádmio $(\mathrm{Cd})$, cobre $(\mathrm{Cu})$, cromo $(\mathrm{Cr})$, chumbo $(\mathrm{Pb})$, ferro $(\mathrm{Fe})$, manganês $(\mathrm{Mn})$, níquel $(\mathrm{Ni})$ e zinco $(\mathrm{Zn})$, conforme metodologia apresentada pelo Standard Methods for the Examination of Water and Wastewater (Rice et al., 2012), sendo as mesmas determinadas por meio da técnica de espectrometria por absorção atômica no plasma.

Aplicou-se dois métodos estatísticos multivariados visando classificar os acessos em grupos e auxiliando na identificação das variáveis que influenciam a distribuição das concentrações dos metais nos sedimentos do leito do rio: análise de agrupamentos hierárquica e Análise de Componentes Principais/Análise Fatorial (ACP/AF). Todas as análises multivariadas foram realizadas após a padronização das variáveis em que cada uma ficou com média 0 e variância unitária (1). 
De início, realizou-se o processamento da análise de agrupamento por método hierárquico nos dados originais já normalizados, incluindo todas as variáveis explicativas do sedimento e adotando-se a distância euclidiana como medida de semelhança entre as amostras, além de utilizar o método de Ward para discriminar a ligação de grupos, consistindo em adotar uma quantidade de grupos que melhor caracterizasse a estrutura de grupos, após uma série de agrupamentos sucessivos, aos quais os elementos são agregados. O resultado da análise foi apresentado em forma gráfica (dendrograma) que auxiliou na identificação dos agrupamentos.

A ACP foi utilizada para explicar a estrutura de variâncias contidas nas variáveis originais, que resultam em um conjunto menor de combinações lineares ortogonais (Barros et al., 2002). A ACP permitiu condensar a maior quantidade de informações originais em duas variáveis latentes ortogonais, denominadas componentes principais, que são combinações lineares das variáveis originais criadas com os dois maiores autovalores da matriz de covariância dos dados, reduzindo, desta forma, a dimensionalidade do conjunto de variáveis e facilitando a interpretação da independência entre elas, possibilitando a construção de gráficos biplot. $\mathrm{O}$ critério adotado para a escolha do número de componentes foi selecionar aquelas que apresentaram autovalores acima de 1, pois são as mesmas que geram componentes com quantidade relevante de informação das variáveis originais e conseguiram sintetizar uma variância acumulada acima de $70 \%$ (Hair et al., 2009).

Em geral, as componentes que compõem a matriz apresentam valores de difícil interpretação. Esta limitação foi superada pelo procedimento de transformação ortogonal (rotação da matriz dos pesos fatoriais), gerando uma nova matriz, de mais fácil interpretação. $\mathrm{O}$ processo maximiza a variância entre as componentes, alterando a raiz característica sem afetar a proporção da variância total explicada pelo conjunto. O modelo de rotação ortogonal varimax foi adotado devido sua facilidade de interpretação, 
aproximando as cargas da matriz em 1 ou -1, facilitando a interpretação, pois elimina valores intermediários (Rencher, 2002; Hair et al., 2005; Lopes et al., 2009).

Empregou-se também a análise de comunalidade, que é a estimativa da variância compartilhada, ou em comum, entre as variáveis representadas pelos fatores obtidos (Andrade et al., 2005), variando entre 0 e 1 . Desse modo, quanto mais próximas de um estiverem as comunalidades, melhor ajustado estará o modelo (Monteiro \& Pinheiro, 2004).

Para as análises de dados foram utilizados a linguagem e o ambiente R, versão 3.2.3. (R. Development Core Team, 2015). Na execução dessas análises e da técnica de análise de componentes principais foram utilizadas funções princomp e prcomp.

\section{Resultados e discussão}

As concentrações dos metais pesados analisados foram apresentadas na Tabela 2, ressaltando-se que o elemento $\mathrm{Cd}$ não foi detectado, estando ausente nos pontos avaliados, corroborando com Paiva et al. (2010) que, ao avaliarem o mesmo trecho em análise, não detectaram $\mathrm{Cr}$ e $\mathrm{Cd}$ em sedimento.

Verifica-se que as concentrações dos elementos em estudo nos sedimentos apresentaram elevado coeficiente de variação, conforme classificação de Gomes (2000). Tal fato, pode ser justificado em função do material de origem da formação geológica, associado com a pressão antrópica proveniente dos diversos empreendimentos situados na área urbana consolidada, contribuindo com a descarga de resíduos e efluentes não tratados no corpo hídrico, corroborando com os apontamentos de Barbosa et al. (2010). Já Morais et al. (2010), relatam a existência do descarte de efluentes domésticos e industriais, além de abatedouro de boi e 
frango, de salinas e de Carcinicultura, em especial esgotos in natura nas suas águas.

Tabela 2. Características químicas dos teores médios de metais pesados do rio ApodiMossoró no trecho urbano de Mossoró-RN

\begin{tabular}{ccccccccc}
\hline Variável & $\mathrm{Cr}$ & $\mathrm{Cu}$ & $\mathrm{Mn}$ & $\mathrm{Ni}$ & $\mathrm{Pb}$ & $\mathrm{Zn}$ & $\mathrm{Fe}$ & $\mathrm{Al}$ \\
& $-\cdots-\cdots-\cdots-\cdots-\cdots$ & & \\
Mínimo & 0,00 & 0,00 & 1,15 & 0,00 & 0,00 & 0,88 & 0,16 & 0,22 \\
Média & 1,91 & 2,36 & 64,31 & 0,23 & 0,77 & 58,49 & 2,82 & 2,76 \\
Máximo & 19,30 & 16,43 & 247,24 & 4,09 & 9,32 & 190,11 & 13,99 & 18,57 \\
DP & 4,06 & 3,99 & 67,29 & 0,77 & 1,94 & 58,48 & 3,32 & 3,90 \\
CV (\%) & 212,73 & 169,47 & 104,63 & 334,08 & 252,68 & 99,98 & 117,82 & 141,09 \\
\hline
\end{tabular}

DP - Desvio Padrão e CV - Coeficiente de Variação.

De acordo com Bezerra et al. (2013) e Araújo et al. (2012), a partir da entrada da cidade e à jusante desta, em função da grande carga de efluentes domésticos e agroindustriais, lançadas pelos empreendimentos e residências alocadas nas proximidades do corpo hídrico, além da contribuição do lançamento de esgoto clandestino nos canais de drenagem de águas pluviais, aliado ao despejo e lixiviação de defensivos agrícolas que usam fertilizantes químicos em áreas adjacentes a cidade, o que compromete a qualidade da água e os seus sedimentos de leito do corpo hídrico.

Além da presença das atividades antropogênicas nas áreas de mata ciliar às margens do rio, verifica-se a ocorrência de sinuosidade do leito do rio e existência da obra do projeto de tricotomização de alguns trechos da calha do rio em estudo (Figura 2), no qual ocorreu a construção de braços secundários do rio na zona urbana de Mossoró, o que possivelmente contribui aos processos de erosão marginal e assoreamento, aliados ao baixo fluxo de vazão e elevado potencial de sedimentação, proveniente dos taludes sem proteção de mata ciliar. Esta situação acarreta o incremento das cargas de sólidos trazidos pelo deflúvio superficial, promovendo a elevação das concentrações de $\mathrm{Fe}$ e $\mathrm{Al}$. 
Destaca-se a elevada variação do $\mathrm{Ni}, \mathrm{Pb}$ e $\mathrm{Cr}$ sugerindo elevada contaminação de origem antrópica. Ao avaliar o $\mathrm{Ni}$ verificou-se que apenas 3 amostras obtiveram valores superiores a $1 \mathrm{mg} \cdot \mathrm{Kg}^{-1}$, sendo um destas com valor de 4,09 mg. $\mathrm{Kg}^{-1}$, o que poderia ser tratado como um outlier (ponto 22, Figura 2), sendo que o mesmo resulta da pressão antrópica.

Normalmente, o $\mathrm{Pb}$ é fortemente retido pelo solo, no entanto, fatores como quantidade e tipo de matéria orgânica e $\mathrm{pH}$ podem influir no seu transporte para as águas (Azevedo \& Chasin, 2003). Desse modo, as chuvas podem ter reduzido o $\mathrm{pH}$ da água e do solo, facilitando o seu transporte e aumentando a sua concentração na água e deposição no sedimento.

Barbosa et al. (2010), avaliaram as concentrações de metais em diversos efluentes gerados em Mossoró-RN, verificando uma alta concentração de $\mathrm{Pb}$ nos efluentes (acima do Valor Máximo Permitido da Conama 357/2005), indicando que os mesmos contribuem significativamente para a contaminação do corpo aquático.

Já o Cr pode ser decorrente da geologia da região e da difícil migração horizontal desse metal através do solo, uma vez que o mesmo pode formar complexos insolúveis com a matéria orgânica (Azevedo \& Chasin, 2003). Podendo as concentrações do $\mathrm{Cr}$, serem decorrentes da forte retenção de compostos desse metal pelo solo, os quais podem ter sido arrastados para o corpo aquático, em virtude da ausência de mata ciliar.

O Mn apresentou a maior média de concentração em sedimentos, podendo estar presente como resultado de processos naturais envolvendo tanto a erosão como dissolução de minerais contendo $\mathrm{Mn}$, por meio de reações de oxirredução na interface água-sedimento (Antweiler et al., 2012), podendo ainda, ser decorrentes da variação de $\mathrm{pH}$ no corpo aquático, onde esse metal precipita quando um $\mathrm{pH}$ próximo de 7 é atingido, aumentando a concentração do mesmo no sedimento (Paiva et al., 2010). 
Elevadas concentrações de $\mathrm{Zn}$ em áreas agrícolas podem ser atribuídas à sua ampla utilização em fertilizantes, além da prática de atividades de queimadas, tal como o arraste de substâncias surfactantes.

$\mathrm{Na}$ Tabela 3, verificam-se em destaque as variáveis analisadas que apresentaram correlação igual ou acima de 0,5, conforme sugere Hair et al. (2005). Observa-se comportamento similar entre a distribuição desses sedimentos, apresentando relação positiva, com valores de $|r|>0,8$ onde estas apresentaram correlações fortes positivas. Enquanto as correlações que apresentaram 0,5 $<|\mathrm{r}|<0,8$ foram classificadas em moderada; 0,1< $|\mathrm{r}|<0,5$ fraca; $0<|\mathrm{r}|<0,1$ muito fraca, conforme Santos (2007).

Tabela 3. Matriz de correlação linear dos metais pesados

\begin{tabular}{ccccccccc}
\hline & $\mathrm{Cr}$ & $\mathrm{Cu}$ & $\mathrm{Mn}$ & $\mathrm{Ni}$ & $\mathrm{Pb}$ & $\mathrm{Zn}$ & $\mathrm{Fe}$ & $\mathrm{Al}$ \\
\hline $\mathrm{Cr}$ & 1,000 & & & & & & & \\
$\mathrm{Cu}$ & 0,753 & 1,000 & & & & & & \\
$\mathrm{Mn}$ & 0,719 & 0,477 & 1,000 & & & & & \\
$\mathrm{Ni}$ & 0,783 & 0,654 & 0,435 & 1,000 & & & & \\
$\mathrm{~Pb}$ & 0,688 & 0,532 & 0,607 & 0,801 & 1,000 & & & \\
$\mathrm{Zn}$ & 0,332 & 0,404 & 0,467 & 0,041 & 0,130 & 1,000 & & \\
$\mathrm{Fe}$ & 0,868 & 0,770 & 0,836 & 0,535 & 0,616 & 0,521 & 1,000 & \\
$\mathrm{Al}$ & 0,945 & 0,820 & 0,774 & 0,715 & 0,707 & 0,377 & 0,956 & 1,000 \\
\hline
\end{tabular}

Os resultados podem estar relacionados aos despejos de efluentes domésticos enriquecidos com sais e substâncias surfactantes no curso hídrico em questão e à perda de solo da bacia hidrográfica frente às atividades de supressão vegetal.

Com relação à aplicação dos componentes principais, conforme descrito na metodologia, um modelo com os dois primeiros componentes foi adequado para representar pelo menos $83 \%$ da variância acumulada. $\mathrm{Na}$ Figura 5 e Tabela 4, verifica-se a contribuição de cada variável com correlação maior que 0,7 na formação dos componentes, bem como da variância de cada componente. 
Tabela 4. Matriz dos componentes principais das variáveis de metais pesados no rio ApodiMossoró no trecho urbano em Mossoró-RN

\begin{tabular}{cccccccccccc}
\hline Variáveis & $\mathrm{SD}$ & $\mathrm{VE}$ & $\mathrm{VA}$ & $\mathrm{Cr}$ & $\mathrm{Cu}$ & $\mathrm{Mn}$ & $\mathrm{Ni}$ & $\mathrm{Pb}$ & $\mathrm{Zn}$ & $\mathrm{Fe}$ & $\mathrm{Al}$ \\
\hline $\mathrm{CP} 1$ & 2,34 & 68,60 & 68,60 & 0,40 & 0,35 & 0,35 & 0,33 & 0,34 & 0,19 & 0,40 & 0,42 \\
$\mathrm{CP} 2$ & 1,09 & 14,82 & 83,42 & $-0,08$ & 0,02 & 0,23 & $-0,49$ & $-0,36$ & 0,73 & 0,21 & 0,00 \\
\hline
\end{tabular}

DP - Desvio Padrão, VE - Variância Explicada (\%), VA - Variância Acumulada (\%), CP1 Componente Principal 1 e CP2 - Componente Principal 2.

No $\mathrm{CP} 1$ o $\mathrm{Cr}, \mathrm{Cu}, \mathrm{Mn}, \mathrm{Fe}$ e $\mathrm{Al}$ foram as variáveis com maiores cargas (Tabela 4). Este CP explicou 68,60\% da variância dos dados e descreve a matriz geoquímica representada pelos elementos metálicos de origem geoquímica natural (associado com os óxidos de Mn e Fe). O CP2 explicou $14,82 \%$ da variabilidade dos dados e é representado pelo $\mathrm{Ni}, \mathrm{Pb}$ e $\mathrm{Zn}$, denominado de componente de origem antrópica. Isto demonstra que estes elementos têm o mesmo comportamento ou provêm da mesma fonte, o que é enfatizado pelo fato que a amostra 24 , adjacente a pequenas propriedades rurais e descarte de efluentes da carcinicultura, além da presença de biomassa em suspensão, podendo inferir que a origem desses metais no ponto 24 é antropogênica e está relacionada a uma fonte pontual.

Figura 5. Byplot dos pesos de CP1 e CP2 para nove variáveis químicas dos sedimentos do leito do Rio Apodi-Mossoró
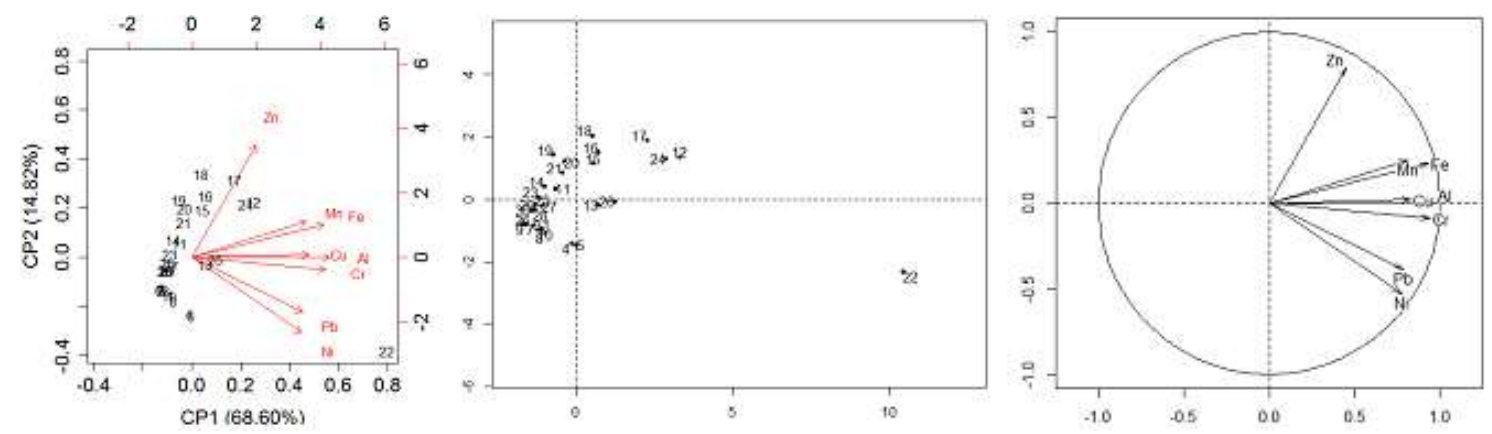

Os teores de metais apresentaram um padrão de distribuição condicionado pelas características hidrodinâmicas de corrente do rio, associado com as atividades antrópicas existentes na área urbana. Em geral, 
as menores concentrações são encontradas nos pontos a montante da área urbana, antes do ponto 10, e a jusante do ponto 27 (Figura 5).

Provavelmente, o aumento da concentração de Zn e Fe está associado com a hidrodinâmica e a taxa de sedimentação, devido à sua localização em uma região de mais baixa energia, o que favorece o acúmulo de sedimento (Silva et al., 2011).

Verifica-se que o ponto 22 apresenta-se isolado na Figura 5, o que remete a um local de poluição pontual, referindo-se a elevadas concentrações de metais adsorvidos e depositados nos sedimentos de leito. Constata-se ainda uma leve heterogeneidade nas concentrações dos metais nos pontos 12, 17 e 24, em que o ponto 12 está a jusante do barramento hidráulico do centro da cidade recebendo carga de poluentes pela drenagem urbana do escoamento superficial das áreas de depósitos de resíduos sólidos localizados próximos aos cursos d'água. Isto demonstra que estes elementos têm o mesmo comportamento ou provêm da mesma fonte, o que é enfatizado pelo fato que a amostra 24, adjacente a pequenas propriedades rurais com a presença da criação de suínos nas margens do rio e descarte de efluentes da carcinicultura, podendo inferir que o ponto 17 está locado próximo a um ponto interceptor da rede de esgoto. Sendo similar nesses pontos a presença de vegetação de aguapés, tal como a ocorrência do processo de eutrofização com biomassa em suspensão.

A fim de promover a otimização e visualização dos escores dos autovetores realizou-se a análise fatorial, a fim de identificar os elementos que exercem maior ação na poluição do corpo hídrico em estudo (Tabela 5).

Tabela 5. Matriz das cargas fatoriais rotacionadas pelo algoritmo Varimax nos dois componentes principais, comunalidades associadas, das variáveis de metais pesados no rio Apodi-Mossoró no trecho urbano em Mossoró-RN

\begin{tabular}{ccccccccc}
\hline Variáveis & $\mathrm{Cr}$ & $\mathrm{Cu}$ & $\mathrm{Mn}$ & $\mathrm{Ni}$ & $\mathrm{Pb}$ & $\mathrm{Zn}$ & $\mathrm{Fe}$ & $\mathrm{Al}$ \\
\hline $\mathrm{F} 1$ & 0,84 & 0,69 & 0,54 & 0,94 & 0,87 & 0,05 & 0,66 & 0,82 \\
$\mathrm{~F} 2$ & 0,44 & 0,47 & 0,65 & $-0,02$ & 0,10 & 0,91 & 0,70 & 0,53 \\
Comunalidades & 0,90 & 0,69 & 0,72 & 0,88 & 0,77 & 0,83 & 0,93 & 0,95 \\
\hline
\end{tabular}

F1 - Fator 1 e F2 - Fator 2. 
Ao considerar valor de corte de 0,7 para os escores (Gardiman Junior, 2015), podendo identificar para o Fator 1 a influência do $\mathrm{Cr}, \mathrm{Ni}, \mathrm{Pb}$ e Al, caracterizando como fator antrópico, possivelmente relacionado ao lançamento de efluentes. Enquanto, para o Fator 2 relata o $\mathrm{Zn}$ e o $\mathrm{Fe}$, denominado fator natural, decorrente aos solos da bacia.

As comunalidades foram altas para as variáveis apresentadas, exceto $\mathrm{Cu}$, assim, a maior parte da variância para cada uma das variáveis foi explicada pelos dois componentes comuns (Tabela 5).

A Figura 6 apresenta o dendrograma com a formação de quatro grupos, ressaltando a influência espacial, com uma provável participação de fontes difusas de contaminação, a partir do corte da distância euclidiana 7,5.

Em que, no Grupo 1 verificou-se a presença de pontos de coleta situados nos extremos do trecho avaliado, estando a montante do centro da cidade ( 1 ao 11) e a jusante do mesmo. No Grupo 2 , tem-se os pontos 12 e 24 os quais remetem respectivamente, ao local de desague da rede de drenagem pluvial e a criação de animais na margem do rio. O Grupo 3 contempla os pontos que estão situados mais próximos do centro da cidade. O Grupo 4 tem isoladamente o ponto 22 , configurado pela dissimilaridade das concentrações dos metais, tal fato decorrente do lançamento da rede de drenagem pluvial, sendo influenciado por fontes difusas de contaminação, associada com às descargas de efluentes. 
Figura 6. Dendrograma resultante da análise hierárquica de agrupamentos com a formação de grupos com base na distância euclidiana

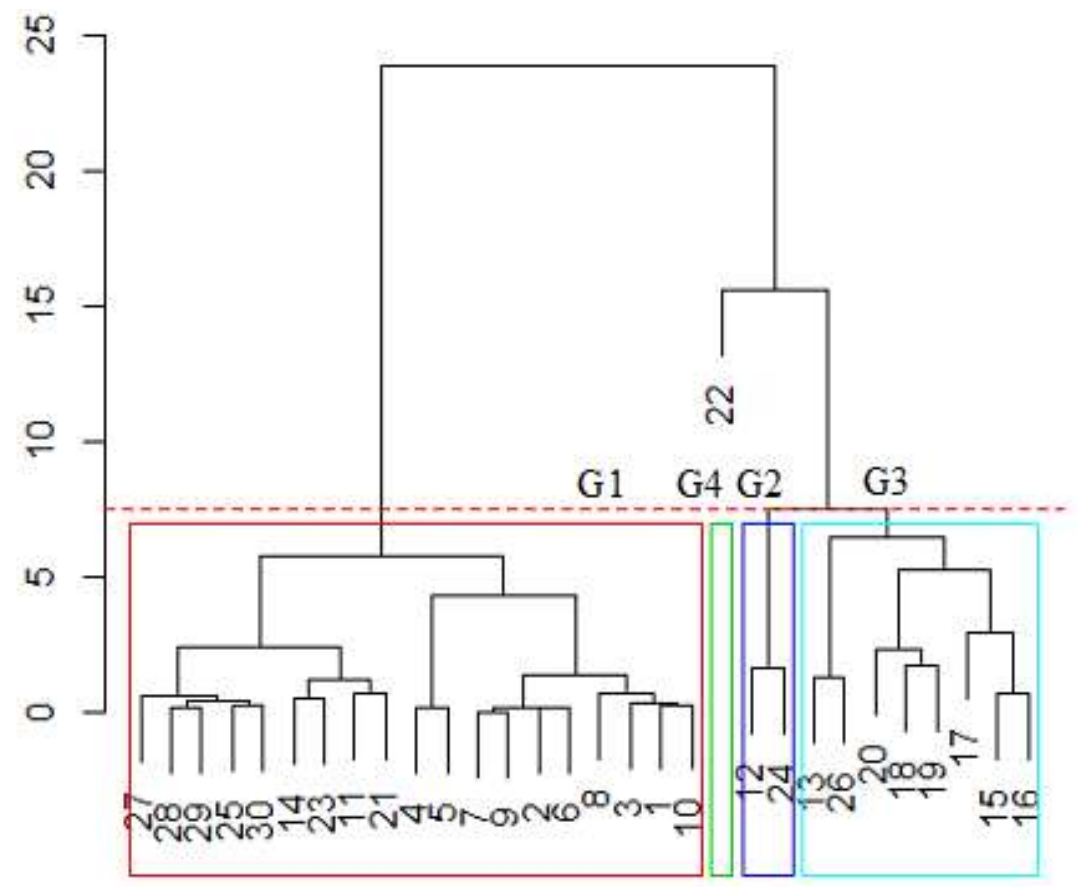

Ressalta-se a importância da análise de agrupamento hierárquico sendo útil para uma classificação confiável dos sedimentos de leito do trecho do rio em estudo, promovendo uma avaliação rápida ao identificar e classificar locais representativos de cada grupo. Propiciando projetar uma melhor estratégia de monitoramento espacial com a redução das amostragens e otimização de custos e processos, tornando mais dinâmico.

Silva (2009) exemplifica que problemas ocorrem com a maioria dos rios que cruzam as cidades, pois foram transformados em cloacas e servem para lançamento de resíduos sólidos ou líquidos. Desta forma, o agrupamento auxilia na redução de pontos a serem amostrados em virtude da representatividade e similaridade entre os pontos iniciais amostrados, auxiliando nas práticas de monitoramento reduzindo custos e tempo. 


\section{Consclusões}

A distribuição das concentrações dos parâmetros geoquímicos nos sedimentos do rio Apodi-Mossoró no trecho urbano de Mossoró-RN, foram fortemente influenciados pelas características dos locais de coleta e pela antropocidade.

A proximidade do rio com os centros urbanos faz com que as concentrações de metais dos efluentes poluídos absorvidos por ele seja maior que a sua capacidade de diluição, aumentando o teor de poluentes encontrados retidos nos sedimentos.

A utilização de técnicas estatísticas multivariadas apresentou-se útil para interpretação de processos geoquímicos no corpo hídrico, associados com a pressão antrópica. Permitindo a classificação dos teores de metais nos sedimentos do leito do rio, favorecendo a otimização do procedimento de amostragem para monitoramento, ao formar grupos com locais representativos.

Além de reduzir a dimensionalidade de 9 nove variáveis iniciais para apenas 2 componentes principais, que explicam $83,42 \%$ da variância total dos dados, tornando mais eficaz e menos dispendioso a caracterização do processo de poluição do trecho do corpo hídrico estudado.

Agrupou-se os pontos amostrados em 4 grupos representativos quanto as características de amostragem, identificando possíveis locais com alterações propiciadas pela ação antrópica. 


\section{Referências}

ALVES, R. I. S. Parâmetros limnológicos, metais e bioagentes patogênicos na Bacia Hidrográfica do Pardo: Avaliação de risco à saúde. Tese (Doutorado em Enfermagem). Ribeirão Preto/USP. 2013, $133 f$.

ANDRADE, E. M.; ARAÚJO, L. F. P.; ROSA, M. F.; DISNEY, W. ALVES, A. B. Seleção dos indicadores da qualidade das águas superficiais pelo emprego da análise multivariada. Engenharia Agrícola, v.27, p.683-690, 2007. https://doi.org/10.1590/S0100-69162007000400011

ANDRADE, E. M. de; PALÁCIO, H. A. Q.; CRISÓSTOMO, L. A.; SOUZA, I. H.; TEIXEIRA, A. S. Índice de qualidade de água, uma proposta para o vale do rio Trussu, Ceará. Revista de Ciência Agronômica, v.36, n.2, p.135-142, 2005.

ANTWEILER, R. C.; TAYLOR, H. E.; ALPERS, C. N. Distribution and geochemistry of selected trace elementes in the Sacramento River near Keswick Reservoir. Chemical Geology, v.298-299, p. 70-78, 2012.

ARAÚJO, D. N.; SILVA, P. C. M.; DIAS, N. S.; LIRA, D. L. C. Estudo da área de preservação permanente do rio Mossoró no sítio urbano de Mossoró-RN por meio de técnicas de Geoprocessamento. Revista Caatinga, v.25, p.177-183, 2012.

ARAÚJO, V. S.; SANTOS, J. P.; ARAÚJO, A. L. C. Monitoramento das águas do Rio Mossoró/RN, no período de abril/2005 a julho/2006. Holos, v.1, n.23, p.4-41. 2007.

AZEVEDO, F. A.; CHASIN, A. A. M. Metais: gerenciamento da toxicidade. São Paulo, Editora Atheneu, 2003. 554p.

BARBosA, A. R. S.; PAIVA, W. D. A.; COSTA, P. H. C. S.; OLIVEIRA, T. M. B. F.; CASTRO, S. S. L. Correlação dos teores de metais presentes em amostras ambientais e efluentes na bacia hidrográfica Apodi/Mossoró - RN. In: Anais. $33^{\text {a }}$ Reunião Anual da Sociedade Brasileira de Química. Águas de Lindóia - SP, 2010.

BEZERRA, J. M.; SILVA, P. C. M.; BATISTA, R. O.; PINTO, C. H. C.; FEITOSA, A. P. Análise dos indicadores de qualidade da água no trecho urbano do Rio ApodiMossoró em Mossoró-RN, Brasil. Semina: Ciências Agrárias, v.34, p.3443-3454, 2013.

COLET, K. M.; SOARES, A. K. Diagnóstico e índices de qualidade ambiental da bacia do córrego do Barbado, Cuiabá-MT. Engenharia Ambiental, v.10, p.22-40. 2013.

COMPANHIA DE TECNOLOGIA AMBIENTAL DO ESTADO DE SÃO PAULO. Significado ambiental e sanitário das variáveis de qualidade das águas e dos sedimentos e metodologias analíticas de amostragem. São Paulo: CETESB, 2008. (Série Relatórios. Apêndice A).

GARDIMAN JUNIOR, B. S. Caracterização do processo de poluição das águas superficiais da Bacia Hidrográfica do Rio Jucu, estado do Espírito Santo, Brasil. Revista Agro@mbiente On-line, v. 9, n. 3, p.235-242, 2015.

GOMES, P. F. Curso de estatística experimental. 14. ed. Piracicaba: Nobel, 2000. 477p.

GUEDES, A. S. H.; SILVA, D. D.; ElESBON, A. A. A.; RIBEIRO, C. B. M.; MATOS, A. T.; SOARES, J. H. P. Aplicação da análise estatística multivariada no estudo da qualidade da água do Rio Pomba, MG. Revista Brasileira de Engenharia Agrícola e Ambiental, v.16, n.5, p.558-563, 2012.

EMBRAPA - Empresa Brasileira de Pesquisa Agropecuária. Sistema Brasileiro de Classificação do Solo. 2.ed. Rio de Janeiro: Embrapa CNPS, 2006. 306p. 
JESUS, H. C.; COSTA, E. A.; MEDONÇA, A. S. F.; ZANDONADE, E. Distribuição de metais pesados em sedimentos do sistema estuarino da Ilha de Vitória-ES. Revista Química Nova, v.27, p.378-386, 2004.

LIMA, M. C.; GIACOMELLI, M. B. O.; SÜPP, V.; ROBERGE, F. D.; BARRERA, P. B. Especiação de Cobre e Chumbo em sedimento do Rio Tubarão (SC) pelo método Tessier. Revista Química Nova, v.24, p.734-742, 2001.

MENDES, A. M. S.; DUDA, G. P.; NASCIMENTO, C. W. A.; LIMA, J. A. G.; MEDEIROS, A. D. L. Acúmulo de metais pesados e alterações químicas em Cambissolo cultivado com meloeiro. Revista Brasileira de Engenharia Agrícola e Ambiental, v.14, p.791796, 2010.

MORAIS, L. A.; Silva, L. M.; Di Souza, L.; Castro, S. S. L. monitoramento espaço temporal da qualidade das águas da bacia hidrográfica do rio Apodi/Mossoró RN. Química no Brasil, v.4, p.70-80, 2010.

OLIVEIRA, T. M. B. F.; SOUZA, L. D.; CASTRO, S. S. L. Dinâmica da série nitrogenada nas águas da bacia hidrográfica Apodi/Mossoró - RN - Brasil. Eclética Química, v. 34, n. 3, p. 17-26, 2009.

PAIVA, W. D. A.; CASTRO, S. S. L.; COSTA, SIllVA, P. H. C.; BARBOSA, A. R. S. Determinação do teor de metais na água e no sedimento do rio Apodi/Mossoró, no perímetro urbano de Mossoró. In: Anais, XVI ENCONTRO DE PESQUISA E EXTENSÃO - XVI ENCOPE/UERN - Mossoró, 2010.

ROCHA, A. B., BACCARO, C.A. D.; SILVA, P. C. M.; CAMACHO, R. G. V. Mapeamento geomorfológico da bacia do Apodi-Mossoró-RN-NE do Brasil. Revista Mercator, v.8, p.201-216. 2009.

SANTOS, C. M. A. Estatística Descritiva - Manual de Auto-aprendizagem, Lisboa: Edições Sílabo, 2007. 261p.

SILVA, M. J.; BEZERRA, P. G.; GARCIA, K. S. Avaliação geoquímica da concentração de $\mathrm{Fe}, \mathrm{Cr}, \mathrm{Pb}, \mathrm{Zn}, \mathrm{Cu}$ e $\mathrm{Mn}$ no sedimento estuarino do rio Jacuípe, Bahia. Cadernos de Geociências, v.8, n.2, p.107-122, 2011.

SILVA, A. P. Comitês de Bacias Hidrográfica dos Rios Jucu e Santa Maria da Vitória. Documento Agenda das Bacias Estratégicas Rios Jucu e Santa Maria da Vitória. Instituto Ecobacia e Instituto Estadual de Meio Ambiente e Recursos Hídricos (IEMA). ES - 2009.

UMETSU, R. K.; PEREIRA, N.; CAMPOS, E. M. F. P.; UMETSU, C. A.; MENDONÇA, R. A. M.; BERNASCONI, P.; CAMARGO, M. F. Análise morfométrica e socioambiental de uma bacia hidrográfica amazônica, Carlinda, MT. Revista Árvore, v.36, p.83-92, 2012 . 